\title{
Reduction of aldehydes and hydrogen cyanide yields in mainstream cigarette smoke using an amine functionalised ion exchange resin
}

\author{
Peter J Branton ${ }^{*}$, Kevin G McAdam, Dinah B Winter, Chuan Liu, Martin G Duke and Christopher J Proctor
}

\begin{abstract}
Background: Cigarette smoking is a well recognized cause of diseases such as lung cancer, chronic obstructive pulmonary disease and cardiovascular disease. Of the more than 5000 identified species in cigarette smoke, at least 150 have toxicological activity. For example, formaldehyde and acetaldehyde have been assigned as Group 1 and Group 2B carcinogens by IARC, and hydrogen cyanide has been identified as a respiratory and cardiovascular toxicant. Active carbon has been shown to be an effective material for the physical adsorption of many of the smoke volatile species. However, physical adsorption of acetaldehyde, formaldehyde and also hydrogen cyanide from smoke is less effective using carbon. Alternative methods for the removal of these species from cigarette smoke are therefore of interest. A macroporous, polystyrene based ion-exchange resin (Diaion ${ }^{\circledR}$ CR20) with surface amine group functionality has been investigated for its ability to react with aldehydes and HCN in an aerosol stream, and thus selectively reduce the yields of these compounds (in particular formaldehyde) in mainstream cigarette smoke.

Results: Resin surface chemistry was characterized using vapour sorption, XPS, TOF-SIMS and ${ }^{15} \mathrm{~N} N \mathrm{NR}$. Diaion ${ }^{\circledR}$ CR20 was found to have structural characteristics indicating weak physisorption properties, but sufficient surface functionalities to selectively remove aldehydes and HCN from cigarette smoke. Using $60 \mathrm{mg}$ of Diaion ${ }^{\circledR}$ CR20 in a cigarette cavity filter gave reductions in smoke formaldehyde greater than $50 \%$ (estimated to be equivalent to $>80 \%$ of the formaldehyde present in the smoke vapour phase) independent of a range of flow rates. Substantial removal of HCN (>80\%) and acetaldehyde (>60\%) was also observed. The performance of Diaion ${ }^{\circledR}$ CR2O was found to be consistent over a test period of 6 months. The overall adsorption for the majority of smoke compounds measured appeared to follow a pseudo-first order approximation to second order kinetics.

Conclusions: This study has shown that Diaion ${ }^{\circledR} \mathrm{CR} 20$ is a highly selective and efficient adsorbent for formaldehyde, acetaldehyde and HCN in cigarette smoke. The reductions for these compounds were greater than those achieved using an active carbon. The results also demonstrate that chemisorption can be an effective mechanism for the removal of certain vapour phase toxicants from cigarette smoke.
\end{abstract}

\section{Background}

Cigarette smoke is an aerosol stream containing an extremely complex mixture of chemicals [1]. Amongst the more than 5000 identified constituents of smoke, approximately 150 of these have been documented as toxicants $[2,3]$. Tobacco smoke toxicants cover a range of chemical groups and functionalities (for example nitrosamines, polynuclear aromatic hydrocarbons and

\footnotetext{
* Correspondence: peter_branton@bat.com

Group Research \& Development, British American Tobacco, Regents Park Road, Millbrook, Southampton SO15 8TL, UK
}

carbonyls) [4-6], as well as a range of volatilities, from permanent gases to compounds with very low vapour pressures at ambient temperatures. In 2001 the Institute of Medicine [7] reported that, since smoking related diseases were dose-related, and because epidemiologic studies show reduction in the risk of smoking related diseases following cessation, it might be possible to reduce smoking related risks by developing potential reduced-exposure products (PREPs). These they defined as (1) products that result in the substantial reduction in exposure to one or more tobacco toxicants and (2), if 
a risk reduction claim is made, products that can reasonably be expected to reduce the risk of one or more specific diseases or other adverse health effects.

From the 1950s onwards many attempts have been made to selectively remove or reduce toxicants from cigarette smoke [8-10]. Adsorption by porous adsorbents is a possible means of removing some of the volatile toxicants from smoke [11]. Active Carbon (AC) is a non-selective adsorbent which is widely used in cigarette filters and can reduce a broad range of volatile smoke constituents with boiling points above $c a$ $-30^{\circ} \mathrm{C}$ to a significant extent via physisorption [12]. However, the difficulty of this challenge should not be underestimated. With cigarette smoke, adsorbents need to operate under high flow rate conditions (approximately $1 \mathrm{~L}$ per min for typical machine-smoking conditions), and therefore very short contact times between smoke constituent and filter adsorbent (of the order of milliseconds). Adsorbents also need to function at the gas-solid interface (i.e. not in solution) and in the presence of thousands of other chemicals in both vapour and particulate phases. Adsorbent surfaces are also susceptible to blocking by condensing smoke aerosol particles. For permanent gases, and smoke toxicants with high vapour pressures at ambient temperatures, such as formaldehyde, acetaldehyde or HCN, physical adsorption has been found to be less effective [13] and alternative routes are required. Porosity and surface chemistry of AC may be tailored to improve these reductions [14]. For example, impregnation of AC using $\mathrm{CuO}$ has been shown to enhance adsorption of $\mathrm{HCN}$ by a chemisorption mechanism $[15,16]$ and has application in personal protective equipment. Chemisorption may therefore represent a viable mechanism for the selective filtration of volatile aldehydes and $\mathrm{HCN}$ in cigarette smoke.

Cigarette smoke contains a number of volatile aldehydes, both saturated compounds such as formaldehyde, acetaldehyde, propionaldehyde and butyraldehyde, and unsaturated compounds such as acrolein and crotonaldehyde. These compounds include established, probable or possible human carcinogens, respiratory, cardiovascular and reproductive or developmental carcinogens (Table 1). Carbonyls in cigarette smoke are mainly generated by combustion of a number of tobacco constituents [5], mostly carbohydrates. In particular it is thought that sugars are major sources of formaldehyde in cigarette smoke [8]. Cellulose has been suggested to be the major precursor of mainstream smoke acetaldehyde [17]. There are some data suggesting that glycerol, a material sometimes added to tobacco as a humectant, is an additional precursor for acrolein [18]. The boiling points and vapour pressures of the most commonly measured carbonyl compounds in cigarette smoke are presented in Table 1, together with typical mainstream yields of these compounds. Although the boiling point of formaldehyde is sub-ambient, $30 \%$ of formaldehyde in the mainstream smoke exiting a filtered cigarette resides in the particulate phase [19] and thus is not available for selective filtration at room temperature. Due to the presence of water vapour, formaldehyde in the particulate phase of smoke exists as the hydrated form, $\mathrm{CH}_{2}$ $(\mathrm{OH})_{2}$ [8]. Acetaldehyde, one of the highest yield constituents of cigarette smoke, exists at or around its boiling point at ambient temperatures, and therefore has a very high vapour pressure. The combination of these two factors makes substantial removal of acetaldehyde from a smoke stream by filter additives a major challenge.

Table 1 Boiling points, toxicity assessments [20] and typical mainstream smoke yields (machine-smoked by following ISO 3308) of commonly measured carbonyl compounds and HCN in cigarette smoke.

\begin{tabular}{|c|c|c|c|c|c|c|c|}
\hline Compound & $\begin{array}{l}\text { Boiling } \\
\text { Point } \\
\left({ }^{\circ} \mathrm{C}\right)[21]\end{array}$ & $\begin{array}{l}\text { Vapour } \\
\text { Pressure } \\
\text { at } 20^{\circ} \mathrm{C} \\
(\mathrm{mm} \mathrm{Hg})\end{array}$ & $\begin{array}{l}\text { Cancer risk } \\
\text { assignment }\end{array}$ & $\begin{array}{l}\text { Non-cancer } \\
\text { risk } \\
\text { assignment }\end{array}$ & $\begin{array}{c}\text { Yield from Kentucky } \\
\text { Reference Cigarette } \\
\text { 2R4F [24] }\end{array}$ & $\begin{array}{l}\text { Range of yields } \\
\text { from UK } \\
\text { cigarettes [25] }\end{array}$ & $\begin{array}{l}\text { Range of yields from a } \\
\text { selection of international } \\
\text { cigarette brands [26] }\end{array}$ \\
\hline & & & & & \multicolumn{3}{|c|}{$\mu \mathrm{g} /$ cigarette under ISO 3308} \\
\hline Formaldehyde & -19.1 & $>760$ & IARC 1 & $\mathrm{RT}, \mathrm{CT}$ & 22 & $<2-56.3$ & $1.6-52.1$ \\
\hline Acetaldehyde & 20.1 & $750[22]$ & $\begin{array}{l}\text { IARC 2B, } \\
\text { EPA-PrHC }\end{array}$ & $\mathrm{RT}, \mathrm{CT}, \mathrm{RDT}$ & 624 & $73-872$ & $32-643$ \\
\hline Propionaldehyde & 48 & $271[22]$ & - & $\mathrm{RT}, \mathrm{CT}$ & 52 & $5.7-62.1$ & $3.3-60.4$ \\
\hline Butyraldehyde & 74.8 & $92[23]$ & - & $\mathrm{RT}, \mathrm{CT}$ & 34 & $5.5-51.2$ & $2.7-47.5$ \\
\hline Acrolein & 52.6 & $210[22]$ & - & $\mathrm{RT}, \mathrm{CT}, \mathrm{RDT}$ & 61 & $4.3-87.8$ & $2.4-61.9$ \\
\hline Crotonaldehyde & 104 & $20[22]$ & EPA - PoHC & $\mathrm{RT}, \mathrm{CT}$ & 16 & $<2-33.3$ & $1.0-28.3$ \\
\hline Acetone & 56.1 & $180[23]$ & - & RT & 265 & $39.1-360$ & $46-335$ \\
\hline 2-butanone & 79.6 & 78 [22] & - & RT, RDT & 63 & $8.2-98.5$ & $3.7-78.0$ \\
\hline$\overline{\mathrm{HCN}}$ & 26 & $620[22]$ & - & $\mathrm{RT}, \mathrm{CT}$ & 109 & $9.1-142$ & $0.8-93.9$ \\
\hline
\end{tabular}

IARC 1 - Group 1, Carcinogenic to humans; IARC 2B - Group 2B, Possibly carcinogenic to humans. EPA-PrHC - Probable human carcinogen; EPA-PoHC - Possible human carcinogen; RT - Respiratory Toxicant; CT - cardiovascular toxicant; RDT - Reproductive or developmental toxicant. 
Hydrogen cyanide has been assigned as both a reproductive and cardiovascular toxicant (Table 1). The precursors of $\mathrm{HCN}$ in smoke are predominantly tobacco nitrate and proteins [27]. $\mathrm{HCN}$ is formed from the combustion of these species at the high temperatures generated during a puff as opposed to the lower temperatures during free smoulder of a burning cigarette [5]. HCN, with a boiling point of $26^{\circ} \mathrm{C}$, will have a very high vapour pressure at ambient temperatures; however, in cigarette smoke $\mathrm{HCN}$ is partitioned between gas and particulate phases of smoke at a ratio of ca 1:1 [5].

The reaction of an amine with an aldehyde is well known in organic chemistry. In this work we report an evaluation of the ability of chemisorption to remove high volatility aldehydes and $\mathrm{HCN}$ from mainstream cigarette smoke. A weakly basic macroporous polystyrene resin cross-linked with divinyl benzene, with surface amine functionality, was identified and assessed as a cigarette filter additive. The material, manufactured by Mitsubishi Chemical Corporation is normally supplied in bead form in an aqueous environment and sold under the trade name Diaion ${ }^{\circledR}$ CR20 (hereafter referred to as CR20). The material is commonly used as an ion exchange resin for waste water treatment because of its affinity towards transition metal ions [28]. To make it suitable for use in a cigarette filter application, it is necessary to remove the water and dry the material to $c a 15 \%$ or less moisture. It offers the potential for the nucleophilic capture of aldehydes from mainstream smoke by forming imines [29] (see equation (1) below), and due to its weakly basic nature it may also be used for the removal of $\mathrm{HCN}$ from the cigarette smoke (equations 2 and 3).

$$
\begin{aligned}
& \mathrm{RCHO}+\mathrm{R}^{\prime} \mathrm{NH}_{2} \rightarrow \mathrm{RCH}=\mathrm{NR}^{\prime}+\mathrm{H}_{2} \mathrm{O} \\
& \mathrm{R}-\mathrm{NH}_{2}+\mathrm{HCN} \rightarrow \mathrm{R}-\mathrm{NH}_{3}{ }^{+} \mathrm{CN}^{-} \\
& \mathrm{R}_{2} \mathrm{NH}+\mathrm{HCN} \rightarrow \mathrm{R}_{2} \mathrm{NH}_{2}{ }^{+} \mathrm{CN}^{-}
\end{aligned}
$$

Other amine functionalised materials have been investigated by us, but the ability to remove smoke aldehydes and $\mathrm{HCN}$ was diminished. The pore size, substrate and amination conditions have all been found to play an important part in maximising the chemisorption using CR20.

\section{Experimental}

\section{Materials}

An overview of the Mitsubishi Chemical Corporation CR20 bead manufacturing process is depicted in Figure 1.

The exact type of amine groups produced by functionalization cannot be precisely controlled and several different types could be present on the resins.

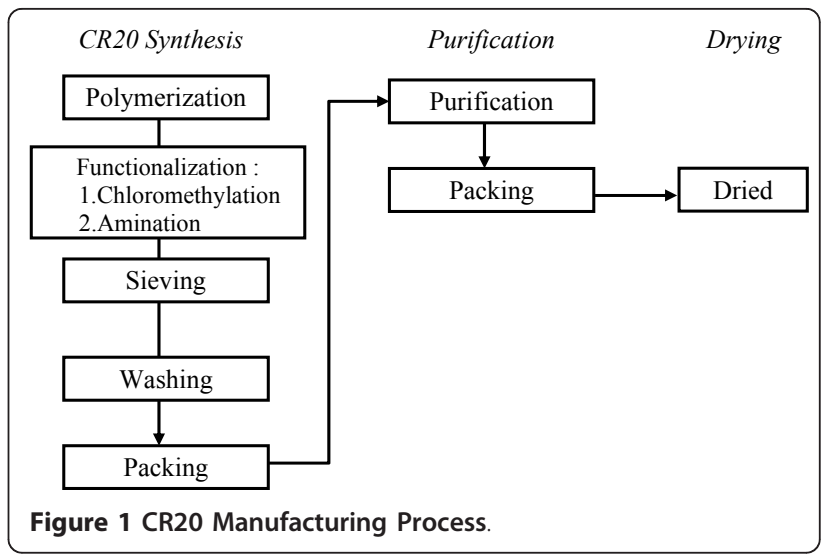

Some examples of possible amine groups are shown in Figure 2:

The CR20 beads used in this study were manufactured and supplied by Mitsubishi Chemical Corporation. Commercial grade CR20 (hereafter referred to as CR20C) was found to have a characteristic odour incompatible with conventional consumer acceptable cigarette smoke character when incorporated into cigarettes. However, modification to the synthesis conditions significantly reduced the intensity of this odour resulting in a "low-odour" grade of CR20 (hereafter referred to as CR20L). The synthesis details of the CR20L can be taken from examples 3, 5 and 6 of the patent [30]. In this work, unless otherwise stated, all results obtained refer to CR20L. This material possessed a bead size of $600 \mu \mathrm{m}$, density of $0.64 \mathrm{~g} / \mathrm{cm}^{3}$, a $15 \%$ by weight water content, and total exchange capacity of $0.92 \mathrm{meq} / \mathrm{cm}^{3}$. The CR20L synthesis has been shown to be reproducible by repeating the manufacturing process 5 times.

Activated carbon used as a control in some of the smoke tests is currently widely used in commercial cigarettes and is based on coconut shell (Ecosorb CX, Jacobi Carbon Ltd). This carbon is microporous with surface area ca $1000 \mathrm{~m}^{2} \mathrm{~g}^{-1}$, pore volume $c a 0.5 \mathrm{~cm}^{3} \mathrm{~g}^{-1}$ and density $c a 0.5 \mathrm{gcm}^{-3}$.

\section{Material Characterisation}

The pore size and distribution of CR20L has been characterized using nitrogen adsorption at $77 \mathrm{~K}$ and mercury porosimetry. Nitrogen isotherms were measured using a Micromeritics ASAP2020 following sample outgassing at $120^{\circ} \mathrm{C}$ for $2 \mathrm{~h}$ prior to isotherm determination. Mercury porosimetry was performed using a Micromeritics Autopore III porosimeter. A pressure range of 0 60,000 psi was used to determine pore sizes from $5 \mathrm{~nm}$ to $360 \mu \mathrm{m}$.

To investigate the chemical composition of CR20L, and its surface functionality, a number of different analytical techniques were employed including titration, 

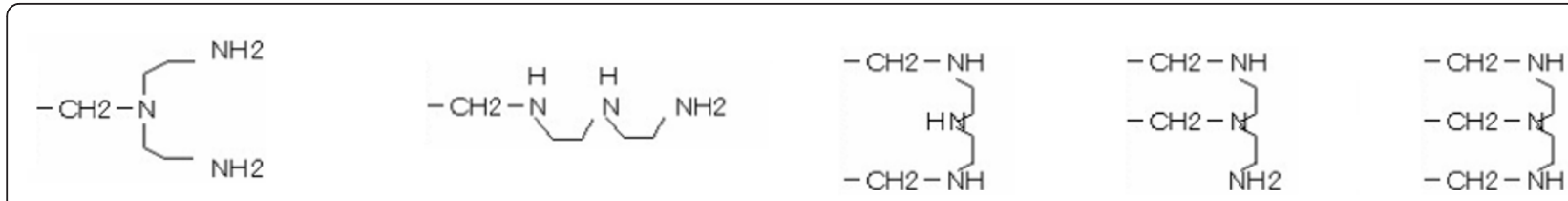

Figure 2 Possible Amine Group Functionalities on CR20.

Time of Flight Secondary Ion Mass Spectroscopy, X-Ray Photoelectron Spectroscopy, ${ }^{15} \mathrm{~N}$ Solid State NMR and water vapour adsorption.

Basicity was determined using titration. $0.5 \mathrm{~g}$ of resin was added to $25 \mathrm{ml}$ of deionised water with $2 \mathrm{~g}$ of Analar $\mathrm{NaCl}$. This was titrated against a standardised $\mathrm{HCl}$ solution $(0.1 \mathrm{M})$ with a $\mathrm{pH}$ meter monitoring the change in acidity. To investigate surface basicity in the gas phase', isothermal calorimetry at $100^{\circ} \mathrm{C}$ using carbon dioxide as the probe was employed. Temperature programmed desorption (TPD) could not be used due to the resins low thermal stability.

Time of Flight Secondary Ion Mass Spectroscopy (TOF-SIMS) was carried out using an ION-TOF TOFSIMS.5 instrument equipped with a bismuth primary ion source. Primary ion energies of $25 \mathrm{keV}$ were used.

X-Ray Photoelectron Spectroscopy (XPS) measurements were performed using a Kratos Axis Ultra spectrometer operating at a base pressure of $3 \times 10^{-9}$ Torr. Resin samples were mounted onto a piece of copper tape fixed to a small piece of silicon wafer measuring ca. $1 \mathrm{~cm} \times 1 \mathrm{~cm}$. The samples were irradiated with monochromatic Al $\mathrm{K} \alpha$ X-rays $(1486.6 \mathrm{eV})$ using a spot size of $220 \mu \mathrm{m}$. Survey spectra were recorded with pass energy of $160 \mathrm{eV}$, from which the surface chemical compositions were determined. In addition, selected high resolution spectra were recorded with pass energy of $40 \mathrm{eV}$, from which the chemical states of those elements were determined. Charge compensation for the electrically insulating specimens was achieved using a magnetically focused beam of electrons as a flood gun current. The standard electron take-off angle used for analysis was $90^{\circ}$ giving a maximum analysis depth in the range of 5 $8 \mathrm{~nm}$. It should be noted that the results will therefore include information on the layers near the surface and not be limited to the surface itself. The quantification model used in the data analysis assumed that the probed sample volume within the probe depth was homogeneous in composition.

Solid State NMR was performed using a Varian VNMRS spectrometer operating at $40.53 \mathrm{MHz}$ for ${ }^{15} \mathrm{~N}$. The CR20L samples were tested as-received with spectral referencing with respect to nitromethane. Sample run times of 16 hours were used on as-received CR20L, and CR20L exposed to smoke. Analysis of CR20L samples post smoke exposure was conducted by removing the CR20L from used cigarette filters; samples were vialed and analysed 1 week after smoking.

Water vapour isotherms were measured at $22^{\circ} \mathrm{C}$ using a Surface Measurement Systems (SMS) DVS-1 instrument. Prior to isotherm determination, approximately $10 \mathrm{mg}$ of the material was dried under flowing air at $22^{\circ} \mathrm{C}$ until a constant weight was obtained. Resolution in water uptake was $0.1 \mu \mathrm{g}$.

\section{CR20C and CR20L evaluation in cigarette filters}

Two series of cigarettes were examined in this work. The first series was constructed to compare the performance of CR20L with $\mathrm{AC}$, and to examine the influence of CR20C filter loading mass on adsorption performance; for both studies the CR20 was placed in a pre-prepared cavity in the cigarette filter (Figure 3). With the second series, which examined the performance of CR20L over extended periods of storage prior to smoking, the CR20L was dispersed amongst the cellulose acetate filter fibres in the configuration ("Dual Dalmatian") commonly used with AC in commercial carbon-filtered cigarettes. This configuration allows for closer contact between the filter additive (CR20) and the triactein plasticiser of the cellulose acetate filter, and is therefore a more rigorous test of changes in the adsorption efficiency over time.

The first series of cigarettes had a circumference of $24.6 \mathrm{~mm}$ and were made up of a $56 \mathrm{~mm}$ long tobacco rod containing a Virginia style tobacco blend (tobacco rod density of $255 \mathrm{mgcm}^{-3}$ at a moisture content of $13 \%)$ and a $27 \mathrm{~mm}$ length three-segment filter $(10 \mathrm{~mm}$ cellulose acetate tobacco at the rod end, a $4 \mathrm{~mm}$ cavity section into which CR20 or AC was inserted, and a $13 \mathrm{~mm}$ cellulose acetate section at the mouth end). Triacetin was used as a plasticizer on cellulose acetate filter rods at loadings of $10 \%$ and $6 \%$ by weight respectively for the mouth end and rod end segments. Cigarette filters were unventilated (i.e., absent of any ventilation holes, which are present in the filter wrappers of many cigarettes, and allow influx of diluting air through the filter during puffing). A commercial $50 \mathrm{CU}$ permeability [31] cigarette paper was used throughout. For the comparison of CR20L with AC as filter additives, a $60 \pm 1 \mathrm{mg}$ sample of CR20L was weighed into the filter cavity of the cigarette as shown in Figure 3. The same weight of coconut based microporous AC with pore volume $c a .0 .5 \mathrm{~cm}^{3} \mathrm{~g}^{-1}$ and similar particle size 
to the CR20L was used in comparator cigarettes. Matching particle sizes were used to ensure comparable filter pressure drops (the impedence to flow caused by the presence of granular material in the filter). For examination of the influence of the mass of CR20C on toxicant removal efficiency $20,40,60$, or $80 \mathrm{mg}$ (all $\pm 1 \mathrm{mg}$ ) of CR20C was weighed into the recessed filter space. Equivalent adsorbate packing density was maintained for these four cigarettes, and therefore the length of the CR20C containing segment increased with increasing additive weight. In each case a $13 \mathrm{~mm}$ cellulose acetate segment was subsequently inserted as the filter mouth end. A control cigarette was also constructed of the same dimensions and composition as the cigarettes above, but with an empty $4 \mathrm{~mm}$ filter cavity section.

It is well established [12] that the efficacy of some filtration adsorbents, such as activated carbon, can decline or "age" over time, particularly in a humid atmosphere. To investigate the ageing of CR20 during storage, cigarettes were manufactured with dimensions of $24.6 \mathrm{~mm}$ circumference, a $56 \mathrm{~mm}$ long tobacco rod containing a Virginia style tobacco blend (tobacco rod density $238 \mathrm{mgcm}^{-3}$ at a moisture content of $13.5 \%$ ), and a $27 \mathrm{~mm}$ length two-segment filter (with a $13 \mathrm{~mm}$ cellulose acetate segment at the mouth end and a cellulose acetate segment of $14 \mathrm{~mm}$ at the tobacco rod end). Both sections were plasticized with $7 \%$ triacetin. The tobacco rod end section of the filter also contained $56 \mathrm{mg}$ of CR20L distributed evenly throughout the cellulose acetate fibres at a loading of $4 \mathrm{mg} / \mathrm{mm}$ filter length. Filters were ventilated to $50 \%$ at a distance $13 \mathrm{~mm}$ from the mouth end to give a $5 \mathrm{mg}$ tar product. A commercial $50 \mathrm{CU}$ cigarette paper was employed. Control cigarettes were made with the same tobacco rod construction, but the filters were a single section $(27 \mathrm{~mm})$ rod of cellulose acetate plasticized with $7 \%$ triacetin, and no CR20.
Following cigarette filter preparation, storage conditions were kept constant for each cigarette examined in this work until smoking. For experiments comparing $\mathrm{AC}$ and CR20L, and experiments examining the influence of CR20C weight on filtration efficiency, all cigarettes were conditioned at $22^{\circ} \mathrm{C}$ and $60 \%$ Relative Humidity for a period of three weeks prior to smoking to allow for consistency with other studies [14,32]. For the ageing study, cigarettes were packed after manufacture and stored at $22^{\circ} \mathrm{C}$ and $60 \%$ Relative Humidity prior to machine-smoking under ISO conditions (see below) at time intervals of 4, 8, 12, 20 and 28 weeks following manufacture. All cigarettes were removed from their packaging and conditioned at $22^{\circ} \mathrm{C}$ and $60 \%$ Relative Humidity for a minimum of 48 hours prior to smoking.

Two smoking regimes were employed to measure mainstream smoke yields from these cigarettes. Mainstream smoke yields were firstly measured (mean values of three replicates of 5 cigarettes) using the standard ISO smoking regime [33] (with a puff volume of 35 $\mathrm{cm}^{3}$, puff duration of $2 \mathrm{sec}$ and puff interval of $60 \mathrm{sec}-$ onds) and a Filtrona linear smoking machine. Percentage removals were calculated relative to the cigarette containing an empty filter cavity. Another smoking regime was used to evaluate the removal efficiency at a higher flow rate often referred to as the Health Canada Intense regime (HCI) [34], i.e. using a puff volume of $55 \mathrm{~cm}^{3}$, puff duration of $2 \mathrm{sec}$ and puff interval of 30 seconds, with any filter tip ventilation holes blocked (note that in the current study no filter tip ventilation was used). These different smoking regimes are referred to herein as ISO and HCI.

The smoke particulate phase was collected on a glass filter pad referred to as a Cambridge filter pad and subsequently analysed to determine tar, water and nicotine 
yields. Total carbonyl yields were determined by trapping the smoke from a puff using two liquid impingers of a 2,4 Dinitrophenylhydrazine (2,4 DNPH) solution. Smoke carbonyls were analysed using an HPLC procedure. HCN was analysed by passing the whole mainstream smoke stream through two impingers of sodium hydroxide solution, followed by quantification using a colorimetric reaction and a continuous flow analyser system. Full details of these methods are given elsewhere [35].

\section{Results and Discussion CR20 Characterisation}

Figure 4 shows the nitrogen isotherm for CR20 at $-196^{\circ}$ C. The isotherm was of Type IV, indicating a predominantly macroporous structure with some large mesopores (as denoted by the hysteresis loop at high relative pressure). A BET surface area of $44 \mathrm{~m}^{2} \mathrm{~g}^{-1}$ was determined, with a pore volume (taken at a relative pressure, $\mathrm{P} / \mathrm{P}_{0}$, of 0.95$)$ of $0.08 \mathrm{~cm}^{3} \mathrm{~g}^{-1}$. By comparison, the coconut-derived active carbon gave a Type I isotherm with surface area of $c a 1000 \mathrm{~m}^{2} \mathrm{~g}^{-1}$ and total pore volume of $0.5 \mathrm{~cm}^{3} \mathrm{~g}^{-1}$. Mercury porosimetry cannot be used to investigate micropores, but is a useful technique for an investigation of mesopores and macropores. Mercury porosimetry measurements on CR20 revealed a broad pore size distribution of $25-900 \mathrm{~nm}$ centered at $105 \mathrm{~nm}$ with volume $1.0 \mathrm{of} \mathrm{cm}^{3} \mathrm{~g}^{-1}$ and a bulk density of 0.50 $\mathrm{gcm}^{-3}$. By way of comparison, mercury porosimetry revealed that the $\mathrm{AC}$ used in this work had a broad pore size distribution of $400-3000 \mathrm{~nm}$, centered at 1000 $\mathrm{nm}$, with a volume of $0.1 \mathrm{~cm}^{3} \mathrm{~g}^{-1}$ within this size range and a bulk density of $0.43 \mathrm{gcm}^{-3}$. This shows the highly microporous nature and lack of meso and macropores for the carbon.

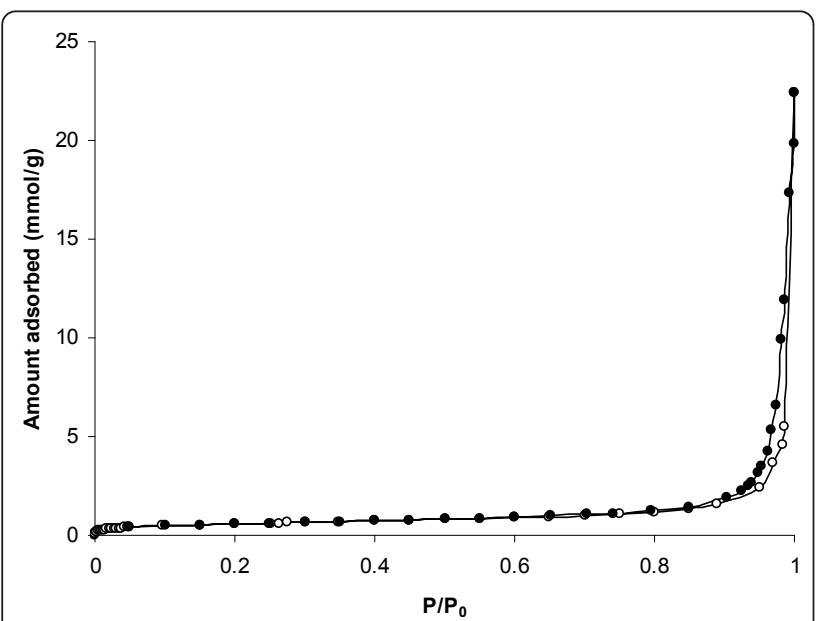

Figure 4 Nitrogen Adsorption at $-196^{\circ} \mathrm{C}$. Open symbols denote adsorption, Closed symbols denote desorption
AC is a widely used adsorbent for the physisorption of many volatile toxicants [36] because of its large surface area and high micropore volume. The data for CR20 show that this material has a significantly lower surface area and hence lower potential for physisorption than the AC for volatile smoke constituents.

In order to characterise the surface functional groups of the resin beads, TOF-SIMS, XPS, and ${ }^{15} \mathrm{~N}$ NMR were employed. Water vapour sorption was also measured to investigate the surface hydrophobicity.

The TOF-SIMS spectra of the resin particle surfaces were characteristic of functionalised polystyrene. The polystyrene characteristic spectral features included distinctive aromatic signals such as those detected at nominal $\mathrm{m} / \mathrm{z} 77+\left(\mathrm{C}_{6} \mathrm{H}_{5}+\right), 91+\left(\mathrm{C}_{7} \mathrm{H}_{7}+\right), 103+\left(\mathrm{C}_{8} \mathrm{H}_{7}+\right)$, $115+\left(\mathrm{C}_{9} \mathrm{H}_{7}+\right), 128+\left(\mathrm{C}_{10} \mathrm{H}_{8}+\right), 141+\left(\mathrm{C}_{11} \mathrm{H}_{9}+\right), 152+$ $\left(\mathrm{C}_{12} \mathrm{H}_{8}+\right), 165+\left(\mathrm{C}_{13} \mathrm{H}_{9}+\right), 178+\left(\mathrm{C}_{14} \mathrm{H}_{10}+\right)$, etc. The presence of surface nitrogen was substantial and most clearly shown by the negative ion signal at $\mathrm{m} / \mathrm{z} 26$ which is principally the $\mathrm{CN}$ - fragment. The presence of organo-nitrogen groups on the resin particle surfaces was also revealed by other nitrogen-containing negative ion signals including the (OCN)- fragment which indicates the presence of some amide/amide-like functionalities. The presence of organo-nitrogen functionalities was also revealed in the positive ion spectra, particularly by the relative intensities of the signals at even $\mathrm{m} / \mathrm{z}$ where $\mathrm{C}_{\mathrm{x}} \mathrm{H}_{\mathrm{y}} \mathrm{N}+$ signals (some indicative of amine/aminelike groups) are major contributors to many of these peaks. "Hydrogen-rich" amine/amine-like groups are likely to include primary amines which may be significant contributors to the $\mathrm{CH}_{2} \mathrm{NH}_{2}+$ signal at $\mathrm{m} / \mathrm{z} 30+$. A signal at $\mathrm{m} / \mathrm{z} 58+\left(\left(\mathrm{CH}_{3}\right)_{2} \mathrm{~N}+\mathrm{CH}_{2}\right)$ is indicative of ammonium-type species at the surface of the particles.

XPS analysis of the resin is presented in Figure 5. The data revealed surface atomic compositions of $82.6 \%$ carbon, $12.8 \%$ oxygen and $3.6 \%$ nitrogen for the as-received CR20 resin (Figure 5). Amine/amide groups represented $3.0 \%$ and quaternary ammonium groups $0.6 \%$. The data showed an appreciable amount of nitrogen from amine and amide groups on the surface. However, the resolution was not sufficient to determine the relative contributions of amine and amide and the classification of these groups (i.e. primary, secondary, tertiary). Detection of the presence of quarternary ammonium groups by XPS agrees with the TOF-SIMS data that ammonium species comprise a small portion of the surface nitrogen functionality. The high oxygen content is difficult to explain. Two previously described sources of oxygen in the resin, amide groups and water, are unable to account for all of the oxygen observed. The additional content of oxygen could possibly result from hydrolysis of the chloromethyl radical in the functionalization step of the CR20 manufacturing process (which is performed 


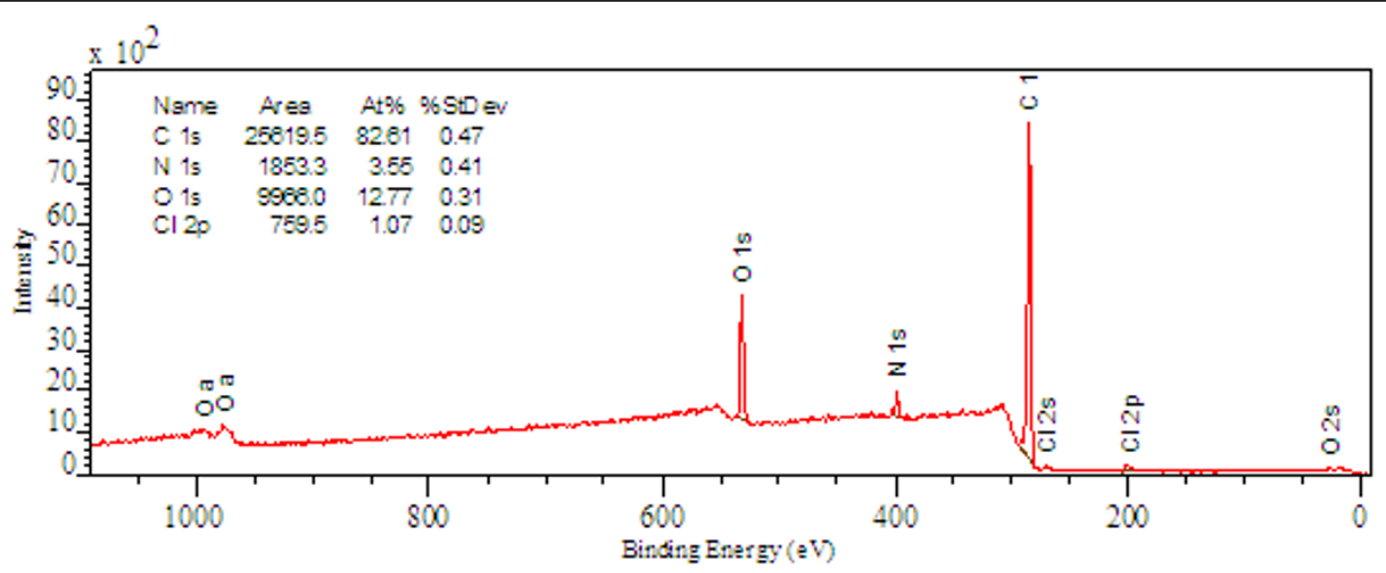

$01 \mathrm{~s}$

$\mathrm{N}$ 1s
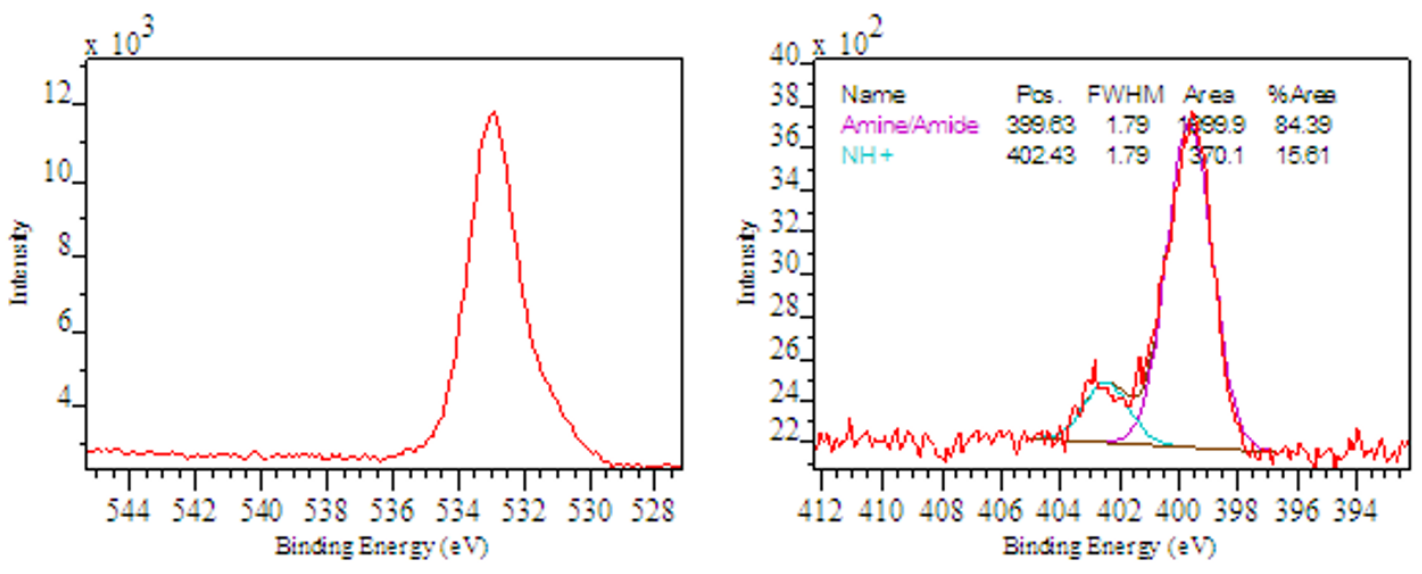

$\mathrm{C} 1 \mathrm{~s}$

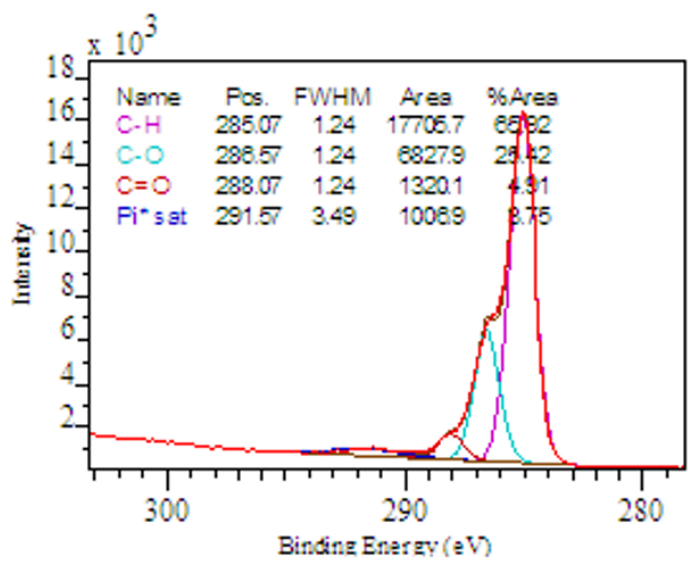

Figure 5 XPS Spectrum of CR20

under alkali conditions, i.e. in the presence of $\mathrm{NaOH}$ ). As an alternative approach to assessing the level of surface functionality, titration experiments revealed a maximum basicity of $1.02 \mathrm{mmol} / \mathrm{g}$. Calorimetry experiments at $100^{\circ} \mathrm{C}$ showed no interactions with surface functional groups and a $\mathrm{CO}_{2}$ gas stream.
The ${ }^{15} \mathrm{~N}$ NMR spectrum for CR20 is shown in Figure 6. As can be seen, there is a broad signal centred at $-344 \mathrm{ppm}$. This broadness could be due to a lack of surface structure order or overlap from multiple species. A shift of $-344 \mathrm{ppm}$ is mid-range for amines but the linewidth makes it impossible to say anything about the 


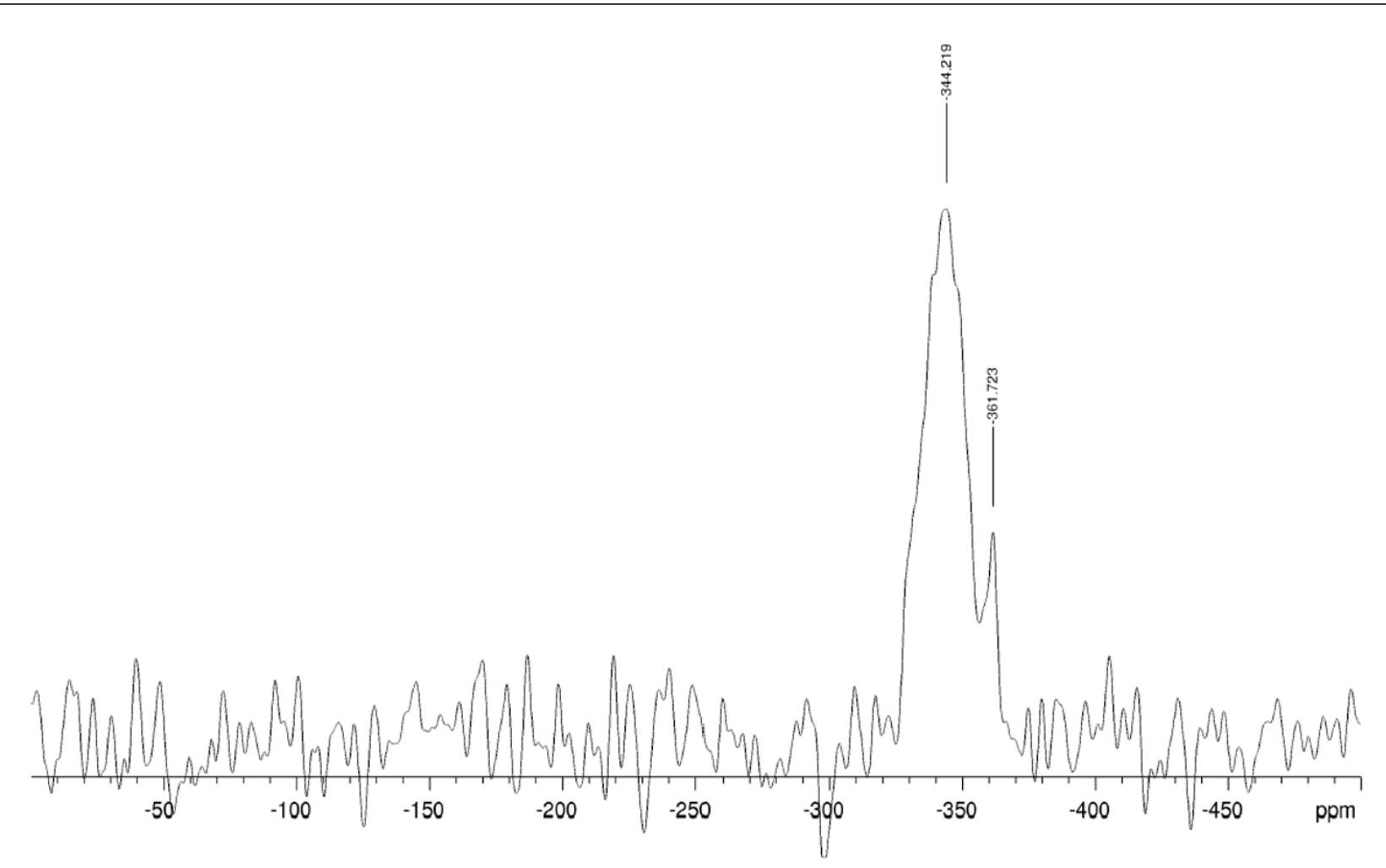

Figure $6{ }^{15} \mathrm{~N}$ NMR Spectrum for CR20.

different amine species. A second, lower intensity line at -362 ppm is consistent with an ammonium species, again qualitatively agreeing with XPS and TOF-SIMS analyses.

The ${ }^{15} \mathrm{~N}$ NMR spectrum for CR20 after exposure to smoke under ISO conditions was very similar in appearance to the as-received resin, with any differences in the spectra comparable to the level of signal noise. Thus it is not possible to identify any changes in the degree of active amine functionality of CR20 due to exposure to cigarette smoke. This may suggest that there is a significant residual capacity available after exposure to the smoke.

Water vapour sorption was measured using a dynamic gravimetric technique at $22^{\circ} \mathrm{C}$ (Figure 7 ). Preferential adsorption of water during ageing or smoking may block the surface and reduce the adsorption efficiency towards some analytes in the smoke stream [12]. The isotherm was 'linear-like' over the relative humidity (RH) range of 0 to $90 \%$ with a small amount of reversible hysteresis. The water uptake at $60 \% \mathrm{RH}$ was $3.5 \%$. In comparison, the microporous activated carbon gave a Type $\mathrm{V}$ isotherm for water adsorption, with an uptake of $24 \%$ by weight of water at $60 \% \mathrm{RH}$, and $35 \%$ at $90 \%$ $\mathrm{RH} . \mathrm{AC}$ is thus more susceptible to ageing when stored in humid environments.
The characterisation of CR20 has revealed a small surface area but extensive surface chemistry, in contrast to AC which has extensive porosity. Substantial physisorption is unlikely with CR20L; however, its extensive and specific surface functionality makes it a good candidate for the selective chemisorption of aldehydes and $\mathrm{HCN}$ in cigarette smoke.

\section{CR20 evaluation in smoke}

Cigarettes containing $60 \mathrm{mg}$ CR20L, $60 \mathrm{mg} \mathrm{AC}$, and cigarettes with an empty cavity were smoked under both

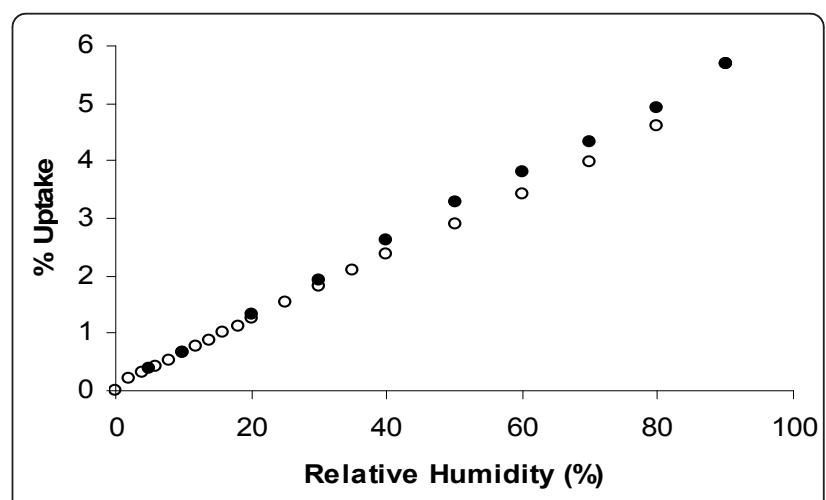

Figure 7 Water Sorption on CR20 at $22^{\circ} \mathrm{C}$. Open symbols denote adsorption, Closed symbols denote desorption 
ISO and HCI smoking regimes in order to compare the adsorption performance of the two filter additives; the data from these measurements are shown in Table 2. The smoke from the two cigarettes were analysed for six different aldehydes and $\mathrm{HCN}$. In addition tar, nicotine and $\mathrm{CO}$ yields were measured to establish whether the addition of the two additives had changed the overall amount of smoke from the cigarettes. Finally, yields of the two ketones, acetone and 2-butanone were also measured; ketones can also react with amine functional groups to form imines. Percentage reductions are shown in bold relative to the yield from the cigarette with the empty cavity (Table 2).

As can be seen in Table 2, the addition of the two filter additives had little effect on the puff number, NFDPM, nicotine, water or CO yields; in other words, the total production of the smoke and the mechanical filtration by the three types of filter were closely matched. The filter additive particle size was large enough not to influence the pressure drop and thus not impede the smoke flow during puffing. It is evident from the data in Table 2 that CR20L is an effective adsorbent of smoke aldehydes and HCN; however, removal of the two ketones is much less efficient (with little removal of acetone observed). In contrast, AC is an effective general adsorbent, offering as efficient removal of the ketones as the aldehydes and HCN. The low removal efficiency for the ketones by CR20L shows that both physisorption ( $c f \mathrm{AC}$ ) and chemisorption mechanisms are poor for ketones using this adsorbent.
Comparing the performance of AC and CR20L shows that the greatest reductions in $\mathrm{HCN}$ and the lower molecular weight smoke aldehydes, acetaldehyde and formaldehyde, are achieved using CR20L. More than half of the formaldehyde was removed from the smoke by CR20L. As the flow rate increases (moving from ISO to HCI smoke regime data) the quantity of volatile smoke toxicants increase, as does the amount removed by both filter adsorbents. However, the efficiency of removal, expressed as the $\%$ of the amount removed relative to the cigarette with the empty cavity filter, decreases for both additives. This is particularly so for smoke analytes with higher vapour pressures. This observation suggests that residence time of the smoke over the adsorbent is an important factor controlling removal efficiency. The exception to this is CR20L and formaldehyde where the proportion of formaldehyde removed appears to be independent of these flow rates and the quantity of smoke.

The effect of CR20 mass on the same smoke analytes was also investigated. As discussed before, a different grade of CR20 (CR20C) was used in this experiment. ISO mainstream smoke data is shown in Table 3 , and percentage reductions are shown in bold relative to the yield from the cigarette with the empty cavity. As can be seen, as the CR20C weight in the filter is increased the aldehyde and HCN yields in smoke decrease systematically but non-linearly. Yields of formaldehyde however remain constant at CR20C weights of $40 \mathrm{mg}$ and higher. The plateauing in formaldehyde removal efficiency at around $70 \%$ is consistent with observations [19] that 70\% of formaldehyde is present in the vapour phase of smoke and $30 \%$ is strongly bound to the

Table 2 Mainstream Smoke Yields using CR20L, AC and an Empty Cavity Filter

\begin{tabular}{|c|c|c|c|c|c|c|}
\hline Smoke regime & ISO & ISO & ISO & $\mathrm{HCl}$ & $\mathrm{HCl}$ & $\mathrm{HCl}$ \\
\hline Additive & None & CR20L & $A C$ & None & CR20L & $A C$ \\
\hline & \multicolumn{6}{|c|}{ Smoke Yields (\% Reduction) } \\
\hline Cig Puff No. & 7.0 & 7.0 & 7.1 & 8.9 & 8.8 & 9.0 \\
\hline NFDPM (mg/cigarette) & 11.9 & 11.0 & 11.6 & 26.3 & 26.1 & 25.8 \\
\hline Nicotine (mg/cigarette) & 0.93 & 0.90 & 0.94 & 1.91 & 1.89 & 1.90 \\
\hline Water (mg/cigarette) & 2.6 & 2.0 & 2.7 & 13.0 & 12.6 & 13.5 \\
\hline CO (mg/cigarette) & 11.2 & 11.1 & 11.5 & 21.7 & 21.9 & 21.7 \\
\hline Acetaldehyde ( $\mu \mathrm{g} /$ cigarette) & 538.3 & 332.3 (38) & 425.5 (21) & 1000 & $763.0(24)$ & $873.6(13)$ \\
\hline Acetone ( $\mu \mathrm{g} /$ cigarette) & 269.7 & $265.2(2)$ & $181.0(33)$ & 496.3 & $532.5(-7)$ & $382.6(23)$ \\
\hline Acrolein ( $\mu \mathrm{g} /$ cigarette) & 62.8 & $37.4(\mathbf{4 0})$ & $39.2(\mathbf{3 8})$ & 128.9 & $92.2(\mathbf{2 8})$ & 91.7 (29) \\
\hline Butyraldehyde ( $\mu \mathrm{g} /$ cigarette) & 34.6 & $26.6(23)$ & 21.9 (37) & 73.5 & $64.4(12)$ & $50.0(32)$ \\
\hline Crotonaldehyde ( $\mu \mathrm{g} /$ cigarette) & 20.8 & $11.5(45)$ & $11.1(47)$ & 48.0 & $35.2(27)$ & $27.9(\mathbf{4 2})$ \\
\hline Formaldehyde ( $\mu \mathrm{g} /$ cigarette) & 42.5 & $19.6(\mathbf{5 4 )}$ & $30.5(\mathbf{2 8})$ & 85.8 & $36.6(\mathbf{5 7})$ & $66.3(23)$ \\
\hline 2-Butanone ( $\mu \mathrm{g} /$ cigarette) & 62.8 & $54.8(13)$ & $38.3(39)$ & 121.5 & $125.3(-3)$ & $84.2(31)$ \\
\hline Propionaldehyde ( $\mu \mathrm{g} /$ cigarette) & 47.4 & $34.7(27)$ & $32.2(32)$ & 88.8 & $75.0(16)$ & $68.6(23)$ \\
\hline HCN ( $\mu \mathrm{g} /$ cigarette) & 123.7 & $56.0(55)$ & $85.3(31)$ & 304.3 & $183.5(\mathbf{4 0 )}$ & $222.3(27)$ \\
\hline
\end{tabular}

NFDPM $=$ Nicotine Free Dry Particulate Matter ('Tar'). 
Table 3 Effect of CR20C Mass in the Filter on Smoke Yields

\begin{tabular}{|c|c|c|c|c|c|}
\hline CR20C (mg) & 0 & 20 & 40 & 60 & 80 \\
\hline & \multicolumn{5}{|c|}{ Smoke Yields (\% Reduction) } \\
\hline Cig Puff No. & 6.1 & 6.2 & 6.2 & 6.2 & 6.3 \\
\hline NFDPM (mg/cig) & 10.7 & 10.4 & 10.7 & 10.7 & 10.6 \\
\hline Nicotine (mg/cig) & 0.92 & 0.94 & 0.98 & 0.96 & 0.95 \\
\hline Water (mg/cig) & 1.7 & 1.3 & 1.7 & 1.6 & 1.4 \\
\hline $\mathrm{CO}$ (mg/cig) & 11.5 & 12.6 & 12.8 & 12.8 & 12.4 \\
\hline Acetaldehyde ( $\mu \mathrm{g} / \mathrm{cig})$ & 551 & $414(25)$ & $273(50)$ & $210(62)$ & $166(70)$ \\
\hline Acetone ( $\mu \mathrm{g} / \mathrm{cig})$ & 262 & $260(1)$ & $233(11)$ & $243(7)$ & $248(5)$ \\
\hline Acrolein ( $\mu \mathrm{g} / \mathrm{cig})$ & 70 & $52(26)$ & $36(49)$ & $28(60)$ & $22(69)$ \\
\hline Butyraldehyde ( $\mu \mathrm{g} / \mathrm{cig})$ & 39 & $30(23)$ & $22(44)$ & $18(54)$ & $15(62)$ \\
\hline Crotonaldehyde ( $\mu \mathrm{g} / \mathrm{cig})$ & 21 & $14(33)$ & $8(62)$ & $6(71)$ & $4(81)$ \\
\hline Formaldehyde ( $\mu \mathrm{g} / \mathrm{cig})$ & 77 & $31(60)$ & $22(71)$ & $21(73)$ & $23(70)$ \\
\hline 2-Butanone ( $\mu \mathrm{g} / \mathrm{cig})$ & 67 & $65(3)$ & 54 (19) & $52(22)$ & $51(24)$ \\
\hline Propionaldehyde ( $\mu \mathrm{g} / \mathrm{cig})$ & 51 & $37(27)$ & $25(51)$ & $19(63)$ & $16(69)$ \\
\hline $\mathrm{HCN}(\mu \mathrm{g} / \mathrm{cig})$ & 145 & $71(51)$ & $36(75)$ & $22(85)$ & $16(89)$ \\
\hline
\end{tabular}

NFDPM = Nicotine Free Dry Particulate Matter ('Tar').

particulate phase. Material in the particulate phase of smoke is generally unavailable for adsorption by filter additives. These data also show the exceptional performance of CR20C for reducing formaldehyde, and that 40 $\mathrm{mg}$ of CR20C appears sufficient under ISO smoking conditions to remove all labile formaldehyde in the smoke stream. The two ketones show differing behaviour when presented with different quantities of CR20C. Acetone shows little increase in removal efficiency as the CR20C weight increases, again showing little chemi- or physisorption with this compound. However, 2-butanone is removed with increasing efficiency by increasing amounts of CR20C in the filter suggesting a low level of chemisorption by CR20C for this ketone.

The results of the ageing study are shown in Table 4. Generally, similar smoke yields were observed for each of the constituents measured from 4 to 28 weeks storage pre-smoking. Some of the constituents showed some increases in their mean values, however a oneway ANOVA analysis followed (where appropriate) by Tukey's HSD multiple comparison approach confirmed that there was little systematic increase in the smoke yields over the time period of this study. The analysis did suggest a small increase in $\mathrm{HCN}$ yields (significant at the $95 \%$ confidence level), but none of the other smoke constituents showed a consistent increase that was significant within the variability of measurement. Further work would be required in order to fully characterise any low level ageing effects with CR20L in cigarette filters. It is nevertheless encouraging to observe the consistent performance of CR20L over the period tested.

The consistency in CR20L's adsorption efficiency over time contrasts with that of $\mathrm{AC}$, where ageing occurs due to water vapour, natural tobacco volatile species and triacetin adsorption blocking the pores within the carbon structure [12]. The differences in ageing characteristics of the two materials are consistent with the substantially lower water adsorption of CR20L in comparison with $\mathrm{AC}$, and the generally lower dependence of a chemisorption mechanism on pore volume, in comparison to physisorption.

Table 4 Effect of Storage Time on Smoke Yields from Cigarettes with 56 mg of CR20L in the Filter

\begin{tabular}{|c|c|c|c|c|c|c|c|c|c|c|c|c|}
\hline \multirow{3}{*}{$\begin{array}{l}\text { Filter Additive } \\
\text { Time Point (weeks) }\end{array}$} & \multirow{2}{*}{\multicolumn{2}{|c|}{ None }} & \multicolumn{10}{|c|}{ CR20L } \\
\hline & & & \multicolumn{2}{|c|}{4} & \multicolumn{2}{|c|}{8} & \multicolumn{2}{|c|}{12} & \multicolumn{2}{|c|}{20} & \multicolumn{2}{|c|}{28} \\
\hline & Yield & SD & Yield & SD & Yield & SD & Yield & SD & Yield & SD & Yield & SD \\
\hline Puff Number & 7.8 & 0.2 & 7.8 & 0.2 & 8.0 & 0.3 & 7.3 & 0.3 & 7.7 & 0.2 & 7.7 & 0.3 \\
\hline NFDPM (mg/cigarette) & 4.2 & 0.3 & 4.5 & 0.3 & 4.9 & 0.2 & 5.0 & 0.8 & 4.1 & 0.2 & 4.9 & 0.4 \\
\hline Nicotine (mg/cigarette) & 0.44 & 0.03 & 0.47 & 0.02 & 0.52 & 0.03 & 0.49 & 0.05 & 0.48 & 0.02 & 0.54 & 0.02 \\
\hline Water (mg/cigarette) & - & N/A & - & 0.05 & 0.3 & 0.04 & 0.2 & 0.04 & 0.2 & 0.03 & 0.2 & 0.03 \\
\hline Carbon Monoxide (mg/cigarette) & 4.8 & 0.3 & 4.6 & 0.3 & 5.0 & 0.2 & 4.7 & 0.4 & 4.6 & 0.2 & 4.7 & 0.2 \\
\hline Acetaldehyde ( $\mu \mathrm{g} /$ cigarette) & 266 & 16.7 & 144 & 13.0 & 124 & 5.3 & 146 & 15.8 & 152 & 11.9 & 164 & 13.8 \\
\hline Acetone ( $\mu \mathrm{g} /$ cigarette) & 138 & 13.9 & 132 & 5.0 & 108 & 2.5 & 122 & 8.0 & 96.3 & 44.8 & 133 & 4.29 \\
\hline Acrolein ( $\mu \mathrm{g} /$ cigarette) & 28.1 & 2.1 & 15.1 & 1.6 & 13.6 & 0.8 & 16.6 & 1.8 & 16.7 & 1.0 & 17.8 & 1.8 \\
\hline Butyraldehyde ( $\mu \mathrm{g} /$ cigarette) & 18.1 & 1.3 & 14.6 & 1.4 & 12.9 & 0.7 & 14.3 & 1.4 & 14.6 & 1.3 & 14.6 & 0.7 \\
\hline Crotonaldehyde ( $\mu \mathrm{g} /$ cigarette) & 6.0 & 0.7 & 2.8 & 0.4 & 1.7 & N/A & 2.1 & 0.4 & 3.7 & 0.7 & 2.08 & 0.5 \\
\hline Formaldehyde ( $\mu \mathrm{g} /$ cigarette) & 10.8 & 1.4 & 6.1 & 0.7 & 6.3 & 0.4 & 6.7 & 0.6 & 6.9 & 0.5 & 6.8 & 0.6 \\
\hline 2-Butanone ( $\mu \mathrm{g} /$ cigarette) & 33.8 & 2.6 & 29.3 & 2.6 & 24.6 & 1.2 & 27.9 & 2.8 & 28.5 & 3.3 & 31.7 & 1.1 \\
\hline Propionaldehyde ( $\mu \mathrm{g} /$ cigarette) & 24.2 & 1.8 & 17.0 & 1.5 & 15.2 & 0.7 & 17.2 & 1.6 & 17.4 & 1.2 & 18.0 & 1.4 \\
\hline HCN ( $\mu \mathrm{g} /$ cigarette) & 32.6 & 2.6 & 9.5 & 1.6 & 8.8 & 1.0 & 10.5 & 0.7 & 13.0 & 2.1 & 14.7 & 3.1 \\
\hline
\end{tabular}


The smoke data from these experiments can also be analysed using a kinetic approach. The general reactions between the CR20 amine functionality and smoke carbonyls and $\mathrm{HCN}$, as written in Equations 1-3, appear to be first order with respect to each reactant. However, it is not possible to conduct a formal second order kinetic analysis of the data because the exact nature of the amine functionality on CR20 has not been accurately quantified, and attempts to quantify reductions in the level of functionality after smoking were unsuccessful. Given the efficient removal of aldehydes and HCN from cigarette smoke, a reasonable hypothesis to test is that there is an excess of amine sites on the surface of the CR20. For the data presented in Table 2, and for the data presented in Tables 2 and 3, the loadings of CR20 in the filters are held constant within a series of cigarettes. Hence a pseudo first order model, as per Equation 4, can be evaluated.

$$
\left[S C_{t}\right]=\left[S C_{0}\right] e^{\left(-k_{n}\left[f_{C R 20}\right] t\right)}
$$

where:

$[\mathrm{SC}]_{0}=$ concentration of smoke constituent prior to contact with CR20

$[\mathrm{SC}]_{\mathrm{t}}=$ concentration of smoke constituent from cigarettes after contact with CR20

$\mathrm{t}=$ residence time of smoke in the CR20 segment of the filter during a puff

$\mathrm{k}_{\mathrm{n}}=$ rate constant for adsorption of smoke constituent $\mathrm{n}$ by CR20 in cigarette filters

$\left[\mathrm{f}_{\mathrm{CR} 20}\right]=$ the concentration of CR20 functional groups within the adsorbent bed of the filter that participated in the adsorption reactions

Integration of Equation (4) gives:

$$
k_{n}\left[f_{C R 20}\right]=\left(\ln \left[S C_{0}\right]-\ln \left[S C_{t}\right]\right) / t
$$

$[\mathrm{SC}]_{0}$ was taken as the yield of constituent from the control cigarettes without adsorbent, $[\mathrm{SC}]_{\mathrm{t}}$ was taken as the yield of constituent from cigarettes containing adsorbent. The puff profile followed a bell shaped flow profile and therefore the residence time was calculated from the averaged flow. Average residence time for a single puff, t, of $c a 0.011 \mathrm{~s}$ for ISO and $c a 0.007 \mathrm{~s}$ for HCI were calculated from the cigarette circumference of $24.6 \mathrm{~mm}$, filter adsorbent bed of $4 \mathrm{~mm}$ for a $60 \mathrm{mg}$ loading, and averaged volumetric flow-rates of $17.5 \mathrm{~cm}^{3}$ / $\mathrm{s}$ and $27.5 \mathrm{~cm}^{3} / \mathrm{s}$ for the ISO and HCI smoking regimes respectively. Residence times changed pro-rata with adsorbent bed length and CR20 mass in the filter. Smoke constituent concentrations were calculated by dividing the per-cigarette yield by the product of the puff volume and the number of puffs per cigarette. As the total surface functional groups are assumed to be in surplus and no change could be observed in the level of active functionality post-smoking, one can assume that [ $\left.\mathrm{f}_{\mathrm{CR} 20}\right]$ was held constant for a set of test cigarettes, and any changes in $\left[\mathrm{f}_{\mathrm{CR} 20}\right]$ due to reaction with smoke challenge gases during smoking are minor. Then, the rate constant $\mathrm{k}$ can be replaced by an effective rate constant $\mathrm{k}_{\mathrm{n}}$ such that

$$
k_{n}^{\prime}=k_{n}\left[f_{C R 20}\right]
$$

The data in Table 3 was used to test the suitability of this pseudo-first order kinetic model. The results of the model test are shown in Figure 8 and Table 5 .

The data in Figure 8 and Table 5 shows that the pseudo-first order model offers a good explanation of the phenomena observed with $\mathrm{HCN}$ and most of the aldehydes $\left(r^{2}>97.5 \%\right.$ in each case). The exception to this is formaldehyde for which a much poorer fit to the data is obtained, and clear evidence exists of non-linearity in the rate equation plot. The model also does not account for the observed behaviour of the ketones, particularly acetone. The effective rate constants for the ketones are also considerably lower than for the aldehydes or $\mathrm{HCN}$, indicating the lower reactivity of CR20C towards these ketones (Tables 2 and 3).

Comparing the performance of CR20L under the two smoking regimes shows good agreement between the calculated rate constants for the different flow-rate and residence time experiments (Table 5). However, once again, formaldehyde differs from the other compounds examined in this work. It is known that over $30 \%$ of formaldehyde in mainstream smoke is produced during the first puff [8]. The treatment of averaging the total smoke formaldehyde yield as above may cause an unacceptable mechanistic deviation from reality. The effective rate constants calculated for AC also show good agreement across the two smoking regimes, in this case for all of the compounds examined. The ability of the model to account for different flow rates and CR20 mass and path lengths suggests that the pseudo-first order model is appropriate for the adsorption processes operating in these cigarette filters.

The rate constants for CR20C are approximately twice as large as for CR20L. This indicates greater reactivity of CR20C, and suggests a greater degree of functionality compared to CR20L. The rate constants for HCN and formaldehyde are higher than those other compounds examined in this work, again exemplifying the reactivity of CR20 towards these species.

The rate constants calculated for AC (Table 5) with the compounds examined in this work show a general trend to increase with decreasing volatility of the adsorbing species; indicating that the vapour pressure of a compound influences the extent to which AC can remove it from a smoke stream. Higher rate constants 


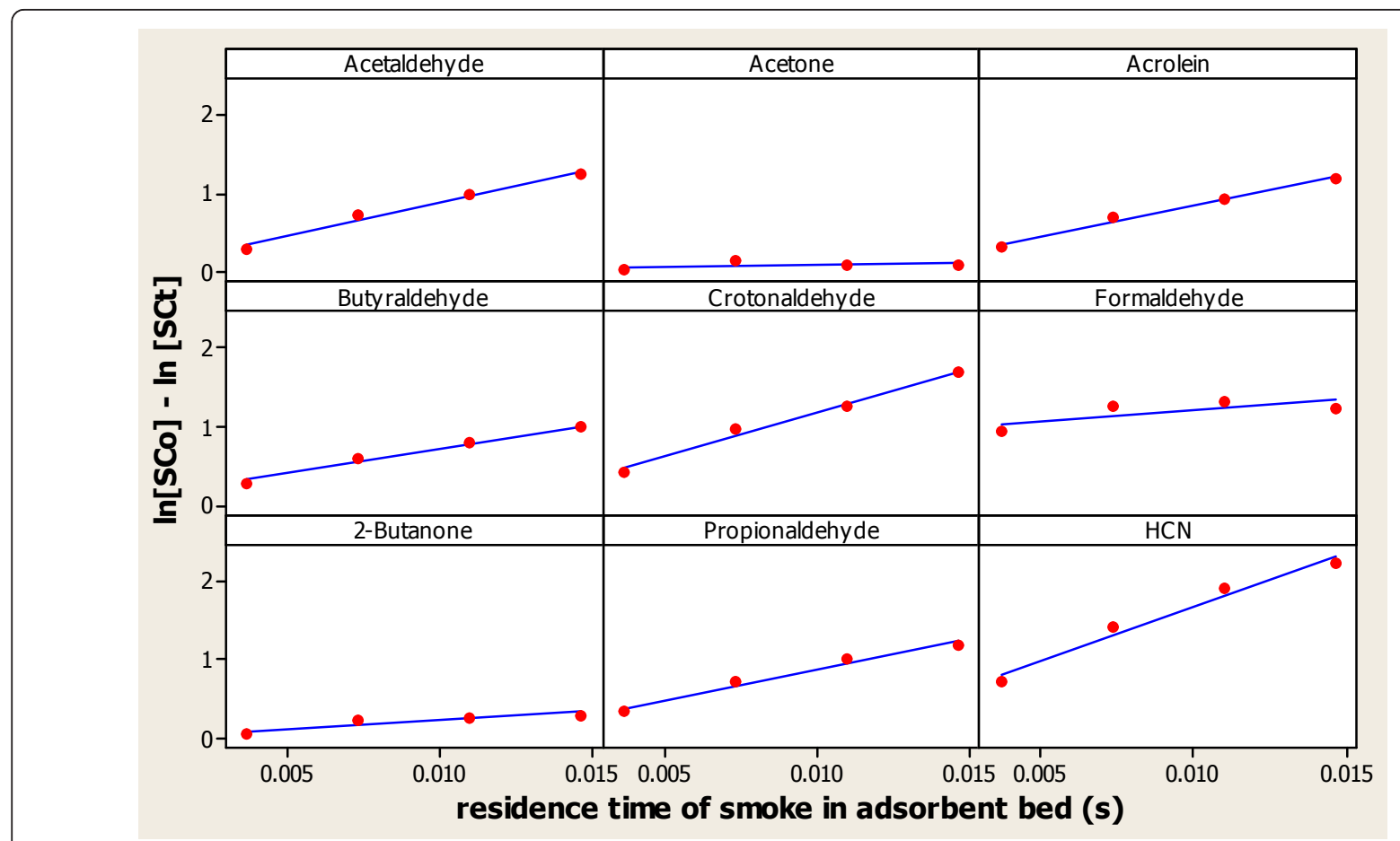

Figure 8 Test of Pseudo-First Order Kinetic Model.

are obtained with CR20 than with AC for the volatile species HCN, formaldehyde and acetaldehyde. Conversely, with the ketones, and compounds with a boiling point in excess of $\sim 50^{\circ} \mathrm{C}, \mathrm{AC}$ is the more effective adsorbent. These observations show that CR20 offers superior performance to AC with some compounds with specific chemistry, but also indicates that some of the superiority of CR20 with these compounds is due to their volatility limiting the effectiveness of the physisorption mechanism with AC.

The incompatibility of formaldehyde with this model could be either due to the fact that $>30 \%$ of formaldehyde is formed during the first puff or that the formaldehyde physical properties such as vapour/particulate partitioning play a major role in determining the effectiveness of selective reduction by filter additives for this compound. It has been reported that under ISO smoking conditions, formaldehyde is present in both particulate phase and vapour phase in mainstream cigarette smoke in the approximate ratio 70:30 [5]. It is considered extremely difficult to selectively reduce chemicals in the particulate phase and it can thus be assumed that CR20 was capable of removing nearly all the formaldehyde present in the smoke vapour phase of these cigarettes.

Table 5 Rate Constants from a Pseudo-First Order Kinetic Analysis

\begin{tabular}{|c|c|c|c|c|c|c|}
\hline \multirow[b]{2}{*}{ Constituent } & \multirow[b]{2}{*}{$\begin{array}{l}\text { Regression coefficient }\left(r^{2}\right) \\
\text { CR20C mass (Table 3) (\%) }\end{array}$} & \multicolumn{5}{|c|}{$\mathrm{k}_{\mathrm{n}}^{\prime},\left(\mathrm{s}^{-1}\right)$} \\
\hline & & $\begin{array}{l}\text { CR20C mass ISO } \\
\text { regime (Table 3) }\end{array}$ & $\begin{array}{l}\text { CR20L ISO } \\
\text { regime (Table 2) }\end{array}$ & $\begin{array}{c}\mathrm{CR} 20 \mathrm{~L} \mathrm{HCl} \\
\text { regime (Table 2) }\end{array}$ & $\begin{array}{l}\text { AC ISO } \\
\text { regime } \\
\text { (Table 2) }\end{array}$ & $\begin{array}{c}\text { AC } \mathrm{HCl} \\
\text { regime } \\
\text { (Table 2) }\end{array}$ \\
\hline Acrolein & 99.1 & 78.5 & 47.1 & 46.2 & 44.1 & 50.2 \\
\hline Butyraldehyde & 98.7 & 63.5 & 23.9 & 17.3 & 42.8 & 56.6 \\
\hline Crotonaldehyde & 98.5 & 112 & 53.8 & 42.7 & 58.3 & 79.1 \\
\hline Acetaldehyde & 98.3 & 83.2 & 43.8 & 37.0 & 22.7 & 20.9 \\
\hline $\mathrm{HCN}$ & 97.7 & 137 & 72.0 & 70.6 & 35.1 & 46.4 \\
\hline Propionaldehyde & 97.5 & 77.3 & 28.3 & 22.5 & 36.4 & 38.4 \\
\hline 2-Butanone & 83.2 & 22.2 & 12.4 & -6.0 & 46.2 & 53.9 \\
\hline Formaldehyde & 52.0 & 112 & 70.3 & 120.0 & 31.4 & 38.4 \\
\hline Acetone & 17.8 & 4.03 & 1.5 & -11.7 & 37.5 & 38.7 \\
\hline
\end{tabular}




\section{Conclusions}

The ion exchange resin CR20 has been characterised using nitrogen adsorption, mercury porosimetry, water sorption, XPS, TOF-SIMS and ${ }^{15} \mathrm{~N}$ NMR. CR20 was found to have structural characteristics indicating weak physisorption properties, but sufficient surface functionalities to selectively remove aldehydes and $\mathrm{HCN}$ from cigarette smoke. Smoking experiments confirmed that CR20 is highly selective and efficient for the filtration of certain aldehydes (in particular formaldehyde) and $\mathrm{HCN}$ in cigarette smoke. For mainstream smoke formaldehyde, no loss in filtration efficiency was observed by increasing the flow rate (from $35 \mathrm{~cm}^{3}$ in a $2 \mathrm{~s}$ puff to 55 $\mathrm{cm}^{3}$ in a $2 \mathrm{~s}$ puff). Reductions in smoke formaldehyde, acetaldehyde and HCN were greater than those that could be achieved using a microporous active carbon operating under a physisorption mechanism. Different grades of CR20 were found to display different levels of smoke constituent removal, suggesting that the degree of active functionality is both material synthesis dependent and a key parameter for removal of these smoke species. A simple pseudo-first order kinetic model fits reasonably well with the performance of CR20 in cigarette filters and agrees with the known adsorption behaviour of the adsorbents tested and the specific properties of the smoke constituents.

\section{Acknowledgements}

We gratefully acknowledge Mitsubishi Chemical Corporation for help and advice and the supply of the Diaion ${ }^{\circledR} \mathrm{C} 20$ material.

\section{Authors' contributions}

PJB jointly wrote and conducted the data analysis with KGM. DBW conducted the ageing study. CL and MGD aided in the data analysis. CJP directed the research.

All authors read and approved the final manuscript.

\section{Competing interests}

The authors declare that they have no competing interests. The authors work for a tobacco company.

Received: 5 January 2011 Accepted: 4 April 2011 Published: 4 April 2011

\section{References}

1. Rodgman A, Perfetti TA: The chemical components of tobacco and tobacco smoke CRC Press, Taylor \& Francis Group, Boca Raton, FL; 2008, 1-928.

2. Fowles J, Dybing E: Application of toxicological risk assessment principles to the chemical constituents of cigarette smoke. Tob Control 2003, 12:424-30.

3. Green CR, Schumacher JN, Lloyd RA Jr, Rodgman A: Comparison of the composition of tobacco smoke and the smokes from various tobacco substitutes. Beitr Zur Tabakforsch Int 2007, 22:258-289.

4. Burns DM, Dybing E, Grey N, Hecht S, Anderson C, Sanner T, O'Connor R, Djordjevic M, Dresler C, Hainaut P, Jarvis M, Opperhuizen A, Straif K: Mandated lowering of toxicants in cigarette smoke: a description of the World Health Organisation TobReg proposal. Tob Control 2008, 17:132-141.

5. Baker RR: Smoke chemistry. In Tobacco: Production, Chemistry and Technology. Volume chapter 12. Edited by: Davis DL, Neilsen MT. Oxford: Blackwell Science; 1999:398-439.
6. Wynder E, Hoffmann D: Tobacco and tobacco smoke: studies in experimental carcinogenesis New York (NY): Academic Press; 1967, 1-730.

7. Stratton K, Shetty P, Wallace R, Bondurant S, (Eds): Clearing the smoke. Assessing the science base for tobacco harm reduction National Academy Press, Washington, D.C; 2001, 1-636.

8. Baker RR: The generation of formaldehyde in cigarettes-Overview and recent experiments. Food Chem Toxicol 2006, 44:1799-1822.

9. Hoffmann D, Hoffmann I, El-Bayoumy K: The less harmful cigarette: A controversial issue. A tribute to Ernst L. Wynder. Chem Res Toxicol 2001, 14:767-790.

10. Wynder EL, Hoffmann D: Tobacco and health-a societal challenge. The New England J Medicine 1979, 300:894-903.

11. Rouquerol F, Rouquerol J, Sing K: Adsorption by powders and porous solids London: Academic Press; 1999, 1-447.

12. Branton P, Bradley RH: Activated Carbons for the Adsorption of Vapours from Cigarette Smoke. Adsorption Science \& Technology 2010, 28:3-21.

13. Branton PJ, McAdam KG, Duke MG, Liu C, Curle M, Mola M, Proctor CJ, Bradley RH: Use of Classical Adsorption Theory to Understand the Dynamic Filtration of Volatile Toxicants in Cigarette Smoke by Active Carbons. Adsorption Science \& Technology

14. Branton PJ, Lu AH, Schüth F: The effect of carbon pore structure on the adsorption of cigarette smoke vapour phase compounds. Carbon 2009, 47:1005-1011.

15. Reucroft PJ, Chiou CT: Adsorption of cyanogens chloride and hydrogen cyanide by activated and impregnated carbons. Carbon 1977, 15:285-290.

16. Barnes PA, Chinn MJ, Dawson EA, Norman PR: Preparation, Characterisation and Application of Metal-doped Carbons for Hydrogen Cyanide Removal. Adsorption Science and Technology 2002, 20:817-833.

17. Seeman Jl, Dixon M, Haussmann HJ: Acetaldehyde in mainstream tobacco smoke: Formation and occurrence in smoke and bioavailability in the smoker. Chemical Research in Toxicology 2002, 15:1331-1350.

18. Carmines L, Gaworski GL: Toxicological evaluation of glycerine as a cigarette ingredient. Food Chem Toxicol 2005, 43:1521-1539.

19. Sakuma H, Kusama M, Shimojima N, Sugawara S: Gas chromatographic analysis of the p-nitrophenylhydrazones of low boiling carbonyl compounds in cigarette smoke. Tob Sci 1978, 22:158-160.

20. Draft initial list of harmful/potentially harmful constituents in tobacco smoke or smokeless tobacco products. [http://www.fda.gov/downloads/ AdvisoryCommittees/CommitteesMeetingMaterials/ TobaccoProductsScientificAdvisoryCommittee/UCM221804.pdf].

21. Lide DR, ed: Physical constants of organic compounds. CRC Handbook of Chemistry and Physics. 89 edition. Boca Raton, CRC Press; 2008, section 3-1.

22. High purity fine chemicals. [http://www.mallbaker.com].

23. Chemical safety information. [http://www.inchem.org]

24. Chen PX, Moldoveanu SC: Mainstream Smoke Chemical Analyses for 2R4F Kentucky Reference Cigarette. Beitrage zur Tabakforschung International 2003, 20:448-458.

25. Gregg E, Hill C, Hollywood M, Kearney M, McAdam K, McLaughlin D, Purkis S, Williams M: The UK Smoke Constituents Testing Study. Summary of Results and Comparison with Other Studies. Beitr zur Tabakforsch Int 2004, 21:117-138.

26. Counts ME, Morton MJ, Laffoon SW, Cox RH, Lipwicz PJ: Smoke composition and predicting relationships for international commercial cigarettes smoked with three machine-smoking conditions. Regul Toxicol Pharmacol 2005, 41:185-227.

27. Norman $V$, Ihrig AM, Larson TM, Moss BL: The effect of some nitrogenous blend components on NO/Nox and HCN levels in mainstream and sidestream smoke. Beitr Tabakforsch Int 1983, 12:55-62.

28. Mitsubishi chemical's ion-exchange resin and separation media products. [http://www.diaion.com].

29. Furniss BS, Hannaford AJ, Smith PWG, Tatchell AR: Vogel's Textbook of Practical Organic Chemistry. fifth edition. Longman Group UK Limited; 1989, 769.

30. Kubota H: Gas adsorbent. Patent Number US2009/0227693 2009

31. CORESTA Recommended Method No 40, 1994, CORESTA Bull. 3/4. [http://www.coresta.org/Recommended_Methods/CRM_40.pdf].

32. Mola M, Hallum M, Branton P: The characterisation and evaluation of activated carbon in a cigarette filter. Adsorption 2008, 14:335-341.

33. International Organization for Standardization: Routine Analytical Cigarette Smoking Machine - Definitions and Standard Conditions Geneva, Switzerland, ISO 3308; 2000. 
34. Health Canada website. [http://www.hc-sc.gc.ca].

35. Research and Development at British American Tobacco.

[http://www.bat-science.com]

36. Bansal RC, Goyal M: Activated carbon adsorption Boca Raton, CRC Press; $2005,1-520$

doi:10.1186/1752-153X-5-15

Cite this article as: Branton et al:: Reduction of aldehydes and hydrogen cyanide yields in mainstream cigarette smoke using an amine functionalised ion exchange resin. Chemistry Central Journal 2011 5:15.

\footnotetext{
Publish with ChemistryCentral and every scientist can read your work free of charge

"Open access provides opportunities to our colleagues in other parts of the globe, by allowing anyone to view the content free of charge." W. Jeffery Hurst, The Hershey Company.

- available free of charge to the entire scientific community

- peer reviewed and published immediately upon acceptance

- cited in PubMed and archived on PubMed Central

- yours - you keep the copyright

Submit your manuscript here: 